\title{
EFFECTS OF POSITIVE EMOTIONS, ACADEMIC SELF EFFICACY AND SELF REGULATED LEARNING ON SATISFACTION WITH LIFE IN MEDICAL STUDENTS
}

\author{
Ahmad Bilala, Muhammad Umair ${ }^{b}$ Muhammad Ateebc, Alina Saif ${ }^{d}$

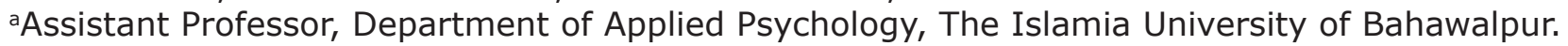 \\ bSenior Registrar, Department of Orthopedics, District Head Quarter Teaching Hospital, Sahiwal. \\ 'Post-Graduate Trainee, Department of Orthopedics, District Head Quarter Teaching Hospital, \\ Sahiwal. \\ ${ }^{\mathrm{d}}$ Research Scholar, Department of Applied Psychology, The Islamia University of Bahawalpur.
}

\section{ABSTRACT:}

BACKGROUND \& OBJECTIVE: The previous studies had found a significant relationship among positive emotions, academic self-efficacy (ASE), self-regulated learning (SRL), and satisfaction with life (SWL). The present study was conducted to predict SWL from positive emotions and SRL in medical students.

METHODOLOGY: The study involved a cross-sectional survey research design. Three hundred medical students from the three medical colleges in Bahawalpur, Lodhran, and Sahiwal were randomly recruited to participate in the study from October 2019 to January 2020. Research Ethics Committee duly approved the study at The Islamia University of Bahawalpur vide No. REC/B-31/2019-F. All the participants filled the necessary informed consent form. Four Likert type scales (a) Dispositional Positive Emotions Scale, (b) Academic Self Efficacy Scale, (c) Efficacy for Self Regulated Learning Scale, and (d) Satisfaction with Life Scale were appended to a single questionnaireto collect the data. The Statistical Package for the Social Sciences, version 25, was used for statistical analysis. The correlation analysis, multiple regression analysis, and analysis of variance were used to compute results.

RESULTS: The study found a statistically significant positive correlation among positive emotions, ASE, SRL, and SWL in medical students. The positive emotions and SRL significantly predicted SWL while ASE did not significantly predict SWL in medical students. The 4th and 5th-year students showed more positive emotions, and students of 1 st and 4th years showed more SRL than students of other years.

CONCLUSION: The study concluded that both positive emotions and SRL significantly predicted SWL in medical students. There were found significant year-wise differences in both positive emotions and SRL.

KEYWORDS: Self Efficacy, Medical Education, Medical Students, Pakistan.

\section{How to cite this:}

doi: https://doi.org/10.37723/jumdc.v12i2.501

Bilal A, Umair M, Ateeb M, Saif A. EFFECTS OF POSITIVE EMOTIONS, ACADEMIC SELF EFFICACY AND SELF REGULATED LEARNING ON SATISFACTION WITH LIFE IN MEDICAL STUDENTS. jumdc. $2021 ; 12(2): 119-125$.

doi: https://doi.org/10.37723/jumdc.v12i2.501

This is an Open Access article distributed under the terms of the Creative Commons Attribution License (http://creativecommons.org/licenses/by/4.0), which permits unrestricted use, distribution, and reproduction in any medium provided the original work is properly cited 


\section{INTRODUCTION:}

It has been shown that positive emotions lead to enhanced academic self-efficacy and selfregulated strategies in medical students ${ }^{[1]}$. Self-efficacy and self-regulated strategy have been found to guide students' learning in formal settings, such as medical school[2]. Pintrich (2000) defines self-regulated learning as a kind of learning where students set their own goals and guide their learning at their own pace ${ }^{[3]}$. Several previous studies have shown that positive

Emotions influence both academic self-efficacy and self-regulated learning ${ }^{[4]}$. But how positive emotions affect academic self-efficacy and selfregulated learning is not clear yet ${ }^{[5]}$.

The concept of self-efficacy was introduced by Albert Bandura in 1977 and can be defined as the belief in performing a specific action ${ }^{[6]}$. Academic self-efficacy is a sub-concept in self efficacy and is described as the belief of being able to excel in the academic field ${ }^{[7]}$. Some note that high academic self-efficacy leads to self-regulated behaviors, such asself-regulated learning ${ }^{[8,9]}$.

Self-regulated learning is an emerging concept in education [10] first introduced by Bandura [11]. Self-regulation by students involves actively controlling and monitoring study time, learning activities, and cognitive resources such as critical thinking ${ }^{[12]}$. The previous studies show that those medical students who use selfregulatory strategies achieve enhanced positive emotions and greater success in academics and life satisfaction ${ }^{[13]}$. It has been learned that the use of self-regulated strategies in clinical courses yields better academic results and greater life satisfaction ${ }^{[14]}$. Self-regulation also improves the positive emotions and academic self-efficacy of medical students in clinical courses ${ }^{[15]}$.

Life satisfaction is a concept synonymous with subjective well-being and happiness and is currently a leading concept in the presentday positive psychology movement [16]. Life satisfaction can be defined as the cognitive assessment of one's life as happy and satisfied and reflects the quality of one's overall life ${ }^{[17]}$. Fulfilling one's goals and engage in a meaningful and achievement-oriented activity is associated with bringing life satisfaction ${ }^{[16,18]}$. Similarly, medical students experience a sense of life satisfaction when using self-regulation in their medical learning, especially in clinical courses [15].

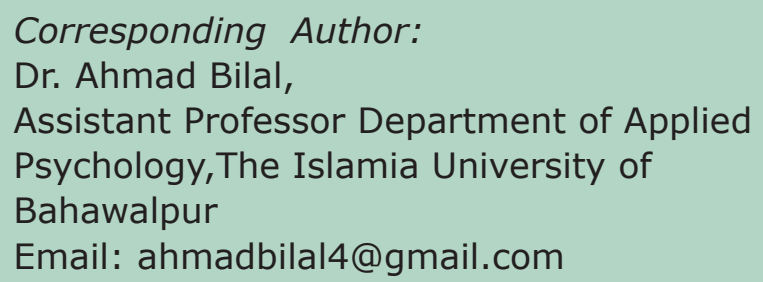

Despite significant associations among positive emotions, academic self-efficacy, and selfregulated learning and their role in bringing satisfaction with life, scant research is available with these variables involving medical students. The present research was conducted to find out the associations among positive emotions, academic self-efficacy, self-regulated learning, and satisfaction with life. The research also aimed at predicting the satisfaction with life from positive emotions, academic self-efficacy, and self-regulated learning in medical students.

\section{METHODOLOGY:}

The cross-sectional survey research design was used in this study. The study was conducted from October 2019 to January 2020 at three medical colleges in Bahawalpur, Lodhran, and Sahiwal. Two of these medical colleges were public sector, while one was from the private sector. The students from 3 medical colleges were included in the sample to give a maximum representation of the South Punjab area and have different crosssections of medical students. Three hundred medical students from 1st to 5thprofessional years were recruited randomly from the three medical colleges. The sample size was calculated using Fluidsurveys sample size calculator with $95 \%$ confidence interval and 5\% margin of error. The sample of 300 instead of recommended 352 medical students could be recruited because of the busy schedule of medical students by the team of researchers at Bahawalpur, Lodhran, and Sahiwal. The mean age of the students was $21.31(\mathrm{SD}=2.04)$ years.

All the participating students signed the written informed consent before enrolling for the study. The medical students from the three medical colleges in Bahawalpur, Lodhran, and Sahiwal, who were 18 years old, were included in the study. In contrast, the medical students from 
other medical colleges were excluded from the study. The Dispositional Positive Emotions Scale (DPES), Academic Self Efficacy Scale (ASES), Efficacy for Self-Regulated Learning Scale (ESRLS), and Satisfaction with Life Scale (SWLS) were appended to a single questionnaire to collect the data. Each participant was required to fill the whole questionnaire in 40 minutes. The DPES is a 6 item Likert-type scale that measures responses about joy in one's life on a Likert scale of 1-7. Higher scores on the scale represent high positive emotions. The Cronbach Alpha reliability of the scale was $0.82^{[19]}$. The ASES contained 11 items designed in Likert-type format from 1-5. The Cronbach's Alpha reliability of the scale was $0.87^{[7]}$. The ESRL scale contained 8 items designed in Likert format,from 1 to 7 with similar Cronbach Alpha reliability ${ }^{[7,20]}$. The SWLS is a 5 item scale designed to assess one's assessment of satisfaction with one's life on a Likert type scale of 1-7. The Cronbach Alpha reliability of the scale was $0.87^{[21]}$.

The Research Ethics Committee duly approved the study of the Department of Applied Psychology at the Islamia University of Bahawalpur vide No. REC/B-31/2019-F. The data were analyzed by the Statistical Package for the Social Sciences, v 25. Pearson correlation was used to see correlation between variables. Multiple ANOVA was used for multiple comparison. Regression was used to predict the variables. The value of $p<0.05$ was taken as significant.

\section{RESULTS:}

The baseline demographic characteristics of the participants have been described in Table-I. A total of 300 medical students participated in the study. The majority of the students $(n=291,97 \%)$ were in $18-24$ years. $194(65 \%)$ students were from the 1-3 professional years, whereas 106 $(35 \%)$ were from the 4 th and 5 th professional years.

Table-I: Frequency Distribution of Demographic Variables $(n=300)$.

\begin{tabular}{|c|c|c|}
\hline Demographic Variables & Characteristics & N (\%) \\
\hline Age (years) & $18-24$ & $291(97.0)$ \\
\cline { 2 - 3 } M=21.31 SD=2.04 & $>25$ & $9(3.0)$ \\
\hline \multirow{3}{*}{ Professional Year Groups } & $1-3$ & $194(64.7)$ \\
\cline { 2 - 3 } & $4-5$ & $106(35.3)$ \\
\hline \multirow{3}{*}{ Professional Years } & 1 & $66(22.0)$ \\
\cline { 2 - 3 } & 2 & $35(11.7)$ \\
\cline { 2 - 3 } & 3 & $93(31.0)$ \\
\cline { 2 - 3 } & 4 & $70(23.3)$ \\
\cline { 2 - 3 } & 5 & $36(12.0)$ \\
\hline
\end{tabular}

Table-II: Correlations among PE, ASE, SRL, and SWL $(n=300)$.

\begin{tabular}{|c|c|c|c|c|c|}
\hline \multirow{2}{*}{ Demo } & & PE & ASE & SRL & SWL \\
\hline \multirow{2}{*}{ PE } & Pearson Correlation & 1 & $.52^{* *}$ & $.44 * *$ & $.49 * *$ \\
\cline { 2 - 5 } & p-value & & .000 & .000 & .000 \\
\hline \multirow{2}{*}{ ASE } & Pearson Correlation & $.52 * *$ & 1 & $.51^{* *}$ & $.27 * *$ \\
\cline { 2 - 5 } & p-value & .000 & & .000 & .000 \\
\hline \multirow{2}{*}{ SRL } & Pearson Correlation & $.44 * *$ & $.51^{* *}$ & 1 & $.43^{* *}$ \\
\cline { 2 - 6 } & p-value & .000 & .000 & & .000 \\
\hline \multirow{2}{*}{ SWL } & Pearson Correlation & $.49 * *$ & $.27 * *$ & $.43^{* *}$ & 1 \\
\cline { 2 - 6 } & p-value & .000 & .000 & .000 & \\
\hline
\end{tabular}

Note. PE = Positive Emotions; ASE = Academic Self Efficacy; SRL = Self-Regulated Learning;

$\mathrm{SWL}=$ Satisfaction with Life

JUMDC Vol. 12, Issue 2, April-June, 2021 
Table-II correlates with positive emotions, academic self-efficacy, self-regulated learning, and satisfaction with life. There was a statistically significant positive correlation among all the study variables. The PE was statistically significantly correlated with ASE $(r(298)=.52, \mathrm{p}<0.001)$, SRL $(r(298)=.44, p<0.001)$, and SWL $(r(298)=.49$, $\mathrm{p}<0.001)$. There was a significant intercorrelation between ASE and SRL $(r(298)=.51$, $\mathrm{p}<0.001$ ). Similarly, both ASE and SRL were also significantly correlated with $\mathrm{SWL}$, respectively $(r(298)=.27, p<0.001 ; r(298)=.43, p<0.001)$.
Note. $\mathrm{PE}=$ Positive Emotions; ASE = Academic Self Efficacy; SRL = Self-Regulated Learning; $\mathrm{SWL}=$ Satisfaction with Life; SE $=$ Standard Error Table-III gives the regression analysis to predict SWL from PE, ASE, and SRL. The overall regression model was found significant ( $R 2$ $=.30, \mathrm{~F}(3,296)=43.31, \mathrm{p}<.05)$. The $\mathrm{PE}$ and SRL were significantly predicted SWL $(t=7.04$, $p<.05) ;(t=5.03, p<.05)$ whereas ASE did not significantly predict $S W L(t=-1.50, p>.05)$.

Table-III: Multiple Linear Regression $(\mathrm{n}=300)$.

\begin{tabular}{|c|c|c|c|c|c|c|c|}
\hline Predictors & $\mathbf{R 2}$ & $F(d f)$ & Sig. & $\boldsymbol{\beta}$ & SE & $\mathbf{t}$ & Sig. \\
\hline PE & \multirow[t]{2}{*}{0.30} & \multirow{2}{*}{$\begin{array}{c}43.31 \\
(3,296)\end{array}$} & \multirow[t]{2}{*}{$<0.001$} & 0.34 & 0.04 & 7.04 & $<0.001$ \\
\hline ASE & & & & & 0.04 & -1.50 & 0.13 \\
\hline SRL & & & & 0.16 & 0.03 & 5.03 & $<0.001$ \\
\hline
\end{tabular}

Table-IV: Analysis of Variance $(n=300)$.

\begin{tabular}{|c|c|c|c|c|c|c|c|c|}
\hline Prof. Years & 1 & 2 & 3 & 4 & 5 & \multirow[t]{2}{*}{$F(4,295)$} & \multirow[t]{2}{*}{ Sig. } & \multirow[t]{2}{*}{ np2 } \\
\hline Variables & $M(S D)$ & $M$ (SD) & $M(S D)$ & $M$ (SD) & $M$ (SD) & & & \\
\hline PE & $\begin{array}{l}28.92 \\
(6.21) \\
\end{array}$ & $\begin{array}{l}28.22 \\
(5.94) \\
\end{array}$ & $\begin{array}{l}27.18 \\
(6.49) \\
\end{array}$ & $\begin{array}{l}29.40 \\
(5.41) \\
\end{array}$ & $\begin{array}{c}30.88 \\
(6.61) \\
\end{array}$ & 2.85 & 0.02 & 0.03 \\
\hline ASE & $\begin{array}{l}35.92 \\
(6.62) \\
\end{array}$ & $\begin{array}{l}37.45 \\
(7.43) \\
\end{array}$ & $\begin{array}{l}33.97 \\
(7.33) \\
\end{array}$ & $\begin{array}{l}35.95 \\
(7.02) \\
\end{array}$ & $\begin{array}{l}35.80 \\
(7.79) \\
\end{array}$ & 1.83 & 0.12 & 0.02 \\
\hline SRL & $\begin{array}{r}36.27 \\
(8.44) \\
\end{array}$ & $\begin{array}{l}33.57 \\
(7.08) \\
\end{array}$ & $\begin{array}{l}32.32 \\
(8.91) \\
\end{array}$ & $\begin{array}{c}36.11 \\
(9.05) \\
\end{array}$ & $\begin{array}{c}32.55 \\
(10.30) \\
\end{array}$ & 3.13 & 0.01 & 0.04 \\
\hline SWL & $\begin{array}{l}22.39 \\
(4.45)\end{array}$ & $\begin{array}{l}21.14 \\
(5.83)\end{array}$ & $\begin{array}{l}20.23 \\
(4.91)\end{array}$ & $\begin{array}{l}22.04 \\
(4.81)\end{array}$ & $\begin{array}{l}21.41 \\
(6.34)\end{array}$ & 2.13 & 0.07 & 0.02 \\
\hline
\end{tabular}

Note. PE = Positive Emotions; ASE = Academic Self Efficacy; ESRL = Self-Regulated Learning; SWL $=$ Satisfaction with Life; $M=$ Mean; $S D=$ Standard deviation; $n p 2=$ Effect size

Table-IV describes the results of a one-way analysis of variance (ANOVA). Both PE and SRL were found to be significantly different for 1 st to 5 th professional years medical students respectively $(F(4,295)=2.85, p=0.02$, $\eta \mathrm{p} 2=0.03) ;(\mathrm{F}(4,295)=3.13, \mathrm{p}=0.01, \mathrm{np} 2=0.04)$.
The students in the 4th and 5th professional years were high on $\mathrm{PE}$, respectively $(29.40 \pm 5.41$; $30.88 \pm 6.61)$. Similarly, the students in nonclinical and clinical 1st year of studies were high on $S R L$, respectively $(36.27 \pm 8.44 ; 36.11 \pm 9.05)$. 


\section{DISCUSSION:}

The present study aimed to find a relationship among positive emotions, academic selfefficacy, self-regulated learning, and life satisfactionamong medical students.Positive emotions are an important aspect of one's living and lead to experience satisfaction with life. Positive emotions and satisfaction with life are essential components of a person's life ${ }^{[1]}$. So, the need for positive emotions and satisfaction with life for medical studentscannot be underestimated. Medical studies take a toll on students' lives. Self-efficacy in the academic domain and self-regulated learning contribute directly to the quality of life and satisfaction with medical students' lives. Those medical students perform better in studies who experience positive emotions ${ }^{[15]}$. The present study found a positive correlation between positive emotions with both academic self-efficacy and self-regulated learning. The previous studies documented similar findings ${ }^{[19]}$.

Satisfaction with life is the assessment of one's overall happiness in life. The most significant source of satisfaction with life for a medical student is performing in the academic domain. The present study showed a significant positive relationship between positive emotions and satisfaction with life. Satisfaction with life was significantly predicted by positive emotions and self-regulatedlearning. Those medical students who experienced positive emotions were expected to perform better in academics and experience more satisfaction in life ${ }^{[18,22,23]}$.

There has been a direct link between academic self-efficacy and self-regulated learning in medical students. Those students who experience high self-efficacy are higher on self-regulated learning, thus increasing the possibilities of doing better academically ${ }^{[15]}$. Similarly, the present study also found a significant positive relationship between self-efficacy and self-regulated learning, thus validating the previous findings.

Medical studies require a lot of effort and concentration from students. The students who possess self-efficacy or self-regulated learning monitor and plan their studies on their own. Those students secure better grades as well as develop mastery of medical concepts who exhibit self-regulated learning. Self-regulated learning benefits from deriving good feelings from their self-regulated practices, leading to satisfaction with life. The previous studies point towards the positive role of positive emotions and selfregulated learning in making one satisfied with life ${ }^{[1,24]}$.

The students in different professional years showed varying results regarding positive emotions and self-regulated learning. Interestingly, the students in clinical years were high on positive emotions. It may be attributed to their long stay in the medical institution and their commitment toward life as medical students. The1st and 4th-year students were high on self-regulated learning. These results are interesting and point toward a commitment of 1 st-year students to monitor their studies in a disciplined way.

\section{LIMITATIONS \& RECOMMENDATIONS:}

The present research did not include the variable of academic achievement as an outcome of selfefficacy and predictor of satisfaction with life. The study did not compare male and female medical students. The research could be furthered by increasing the sample size and by including students from other medical colleges in South Punjab, to.

\section{CONCLUSION:}

The positive emotions and self-regulated learning were found to predict satisfaction with life in medical students. Positive emotionsare an important source of academic performance and overall satisfaction with life. The study further concludes that future studies should contain the variable of academic achievement.

\section{ACKNOWLEDGEMENT:}

We owe special thanks to the participating medical colleges' management for allowing us to collect data from their campuses. We are indebted to the active contribution of the medical students from the three medical colleges.

CONFLICT OF INTEREST:All authors declare no conflict of interest.

GRANT SUPPORT \& FINANCIAL

DISCLOSURE: None 


\section{REFERENCES:}

1. Ngwira FF, Gu C, Mapoma HWT, Kondowe W. The role of academic emotions on medical and allied health students' motivated selfregulated learning strategies. Journal of Contemporary Medical Education.2017; 5(1): 23-30. Doi: $10.5455 /$ jcme.20170412124640

2. Pintrich PR, Smith DA, García T, McKeachie W]. A Manual for the Use of the Motivated Strategies for Learning Questionnaire (MSLQ). Ann Arbor: University of Michigan, National Center for Research to Improve Postsecondary Teaching and Learning; 1991:1-79.

3. Pintrich PR. The role of goal orientation in self-regulated learning. In: Boekaerts $M$, Pintrich PR, Zeidner M, editors. Handbook of Self-regulation. San Diego, CA: Academic Press; 2000:451-502.

4. Postareff $L$, Mattsson $M$, Lindblom-Ylänne $\mathrm{S}$, Hailikari T. The complex relationship between emotions, approaches to learning, study success and study progress during the transition to university. Higher Education: The International Journal of Higher Education Research. 2017; 73(3): 441-457. Doi: 10.1007/s10734-016-0096-7.

5. D'Errico F, Paciello M, Cerniglia L. When emotions enhance students' engagement in e-learning processes. Journal of e-Learning and Knowledge Society. 2016;12(4):9-23. Doi: 10.20368/1971-8829/1144

6. Bandura A. Self-efficacy: toward a unifying theory of behavioral change. Psychological Review. 1977; 84(2): 191-215. Doi: 10.1037/0033-295X.84.2.191

7. Zimmerman BJ, Bandura A, Martinez-Pons M. Self-motivation for academic attainment: The role of self-efficacy beliefs and personal goal setting. American Education and Research Journal.1992; 29(3): 663-676. Doi: $10.2307 / 1163261$

8. Demirören M, Turan S, Öztuna D. Medical students' self-efficacy in problem-based learning and its relationship with selfregulated learning. Medical Education Online. 2016; 21: 30049. Doi:10.3402/meo. v21.30049

9. Lourenco D, Ferreira AI. Self-regulated learning and training effectiveness. International Journal of Training and Development. $\quad 2019 ; 23(2)$ : 117-134. Doi: $10.1111 /$ ijtd.12149

10. Demiroren M, Turan S, Teker GTD. Determinants of self-regulated learning skills: the roles of tutors and students. Advances in Physiology Education. 2020;44(1): 93-98. Doi:10.1152/advan.00121.2019.

11. Bandura A. Social cognitive theory: an agentic perspective. Annual Review in Psychology. 2001; 52(1): 1-26. Doi:10.1146/annurev. psych.52.1.1

12. Pintrich PR. A conceptual framework for assessing motivation and self-regulated learning in college students. Educational Psychology Review 2004; 16: 385-407. Doi:10.1007/s10648-004-0006-x

13. Honicke T, Broadbent J. The influence of academic self-efficacy onacademic performance: A systematic review. Educational Research Review. 2016; 17: 6384. Doi:10.1016/j.edurev.2015.11.002

14. Sadoughi M. The Relationship between Academic Self-Efficacy, Academic Resilience, Academic Adjustment, and Academic Performance among Medical Students. Journal of Education Strategies in Medical Sciences. 2018; 11(2): 7-14. Doi: 10.29252/ edcbmj.11.02.02

15. Jouhari Z, Haghani F, Changiz T. Factors affecting self-regulated learning in medical students: a qualitative study. Medical Education Online. 2015; 20(1): 28694. Doi: 10.3402/meo.v20.28694

16. Diener E, Lucas RE, Oishi S. Subjective wellbeing: The science of happiness and life satisfaction. Handbook of Positive Psychology. 2002; 2:63-73.

17. Lyndon MP, Masters T, Yu TC, Shao R, Alyami H, Henning $M$, et al. Medical student motivation and well-being: A systematic review. Education in Medicine Journal. 2016;8(3):1120.Doi: $10.5959 /$ eimj.v8i3.457

18. Wach F-S, Karbach J, Ruffing S, Brünken R, Spinath FM. University students'satisfaction with their academic studies: Personality and motivation matter. Frontiers in Psychology. 2016; 7: 1-12. Doi: 10.3389/ fpsyg.2016.00055 
19. Shiota MN, Keltner D, John OP. Positive emotion dispositions differentially associated with Big Five personality and attachment style. The Journal of Positive Psychology. 2006; 1(2): 61-71.Doi: 10.1080/17439760500510833

20. Chemers MM, Hu L-t, Garcia BF. Academic self-efficacy and first year college student performance and adjustment. Journal of Educational Psychology. 2001; 93(1): 55-64. Doi: $10.1037 / 0022-0663.93 .1 .55$

21. Diener E, Emmons RA, Larsen RJ, Griffin S. The Satisfaction with Life Scale. Journal of Personality Assessment. 1985; 49(1): 71-75. Doi: $10.1207 /$ s15327752jpa4901_13

22. Dalia S, Nathalie C, Lucia R. On what Resources can the Students Rely on: Satisfaction with Life, Self-Esteem and Self-Efficacy. Annals of Psychiatry and Mental Health. 2016; 4(2): 1062.

23. Antaramian S. The importance of very high life satisfaction for students' academic success. Cogent Education. 2017; 4(1): 1307622. Doi:10.1080/2331186X.2017.1307622
24. Agustiani H, Cahyad S, Musa M. Self-efficacy and Self-Regulated Learning as Predictors of Students Academic Performance. The Open Psychology Journal. 2016; 9(1): 1-6.Doi:10. 2174/1874350101609010001

\section{Author's Contribution:}

Ahmad Bilal: Manuscript writing, revising it critically for intellectual content and final approval.

Muhammad Umair: Acquisition of data, Interpretation of data, revising it critically for intellectual content, Final approval.

Muhammad Ateeb: Acquisition of data, analysis of data, drafting the article, final approval.

Alina Saif: Acquisition of data, analysis of data.

Submitted for Publication: $21-10-2020$ Accepted after revision: 05-04-2021 